\title{
Binge eating and purging in first-year college students: Prevalence, psychiatric comorbidity, and academic performance
}

\author{
Riccardo Serra $^{1}$ (1) I Glenn Kiekens ${ }^{2}$ ～Johan Vanderlinden ${ }^{3}$ ～Elske Vrieze ${ }^{3}$ | \\ Randy P Auerbach $^{4,5}$ | Corina Benjet $^{6}$ | Laurence Claes ${ }^{7,8}$ | Pim Cuijpers ${ }^{9}$ \\ Koen Demyttenaere ${ }^{2}$ | David D Ebert ${ }^{10}$ | Lorenzo Tarsitani ${ }^{1}$ | \\ Jennifer Greif Green ${ }^{11}$ ｜ Ronald C Kessler ${ }^{12}$ ｜ Matthew K Nock ${ }^{13}$ | \\ Phillippe Mortier ${ }^{2,14}$ | Ronny Bruffaerts ${ }^{2,15}$ \\ ${ }^{1}$ Department of Human Neurosciences and Mental Health, Sapienza University of Rome, Rome, Italy \\ ${ }^{2}$ Department of Neurosciences, Center for Public Health Psychiatry, KU Leuven, Leuven, Belgium \\ ${ }^{3}$ Universitair Psychiatrisch Centrum KU Leuven, Leuven, Belgium \\ ${ }^{4}$ Division of Child and Adolescent Psychiatry, Columbia University, New York, New York \\ ${ }^{5}$ Division of Clinical Developmental Neuroscience, Sackler Institute, New York, New York \\ ${ }^{6}$ National Institute of Psychiatry Ramon de la Fuente Muñiz, Mexico City, Mexico \\ ${ }^{7}$ Faculty of Psychology and Educational Sciences, KU Leuven, Leuven, Belgium \\ ${ }^{8}$ Faculty of Medicine and Health Sciences, University of Antwerp, Antwerp, Belgium \\ ${ }^{9}$ Department of Clinical, Neuro, and Developmental Psychology, Public Health Research Institute, Vrije Universiteit, Amsterdam, The Netherlands \\ ${ }^{10}$ Department for Psychology, Clinical Psychology and Psychotherapy, Friedrich-Alexander University Erlangen Nuremberg, Erlangen, Germany \\ ${ }^{11}$ Wheelock College of Education and Human Development, Boston University, Boston, Massachusetts \\ ${ }^{12}$ Department of Health Care Policy, Harvard Medical School, Boston, Massachusetts \\ ${ }^{13}$ Department of Psychology, Harvard University, Cambridge, Massachusetts \\ ${ }^{14}$ Health Services Research Unit, IMIM (Hospital del Mar Medical Research Institute), CIBER en Epidemiología y SaludPública (CIBERESP), Madrid, Spain \\ ${ }^{15}$ Institute for Social Research, Population Studies Center, University of Michigan, Ann Arbor, Michigan
}

\section{Correspondence}

Ronny Bruffaerts, Universitair Psychiatrisch Centrum - KU Leuven, Campus Gasthuisberg, Herestraat, 49, B-3000 Leuven, Belgium.

Email: ronny.bruffaerts@med.kuleuven.be

Funding information

Fonds Wetenschappelijk Onderzoek, Grant/ Award Numbers: $1114717 \mathrm{~N}, 1114719 \mathrm{~N}$, $11 \mathrm{~N} 0514 \mathrm{~N}, 11 \mathrm{~N} 0516 \mathrm{~N}$; Koning Boudewijnstichting, Grant/Award Number: 2014-J2140150-102905

\section{Abstract}

Background: Binge eating and purging behaviors (BPB) are common among college students, but evidence is scant on prevalence and associations of BPB with mental health problems and objective academic performance. This study aims to investigate: (a) 12-month prevalence of BPB among college first-year students, (b) comorbidity patterns of BPB with various mental health problems, and (c) the association of BPB with objective academic functioning.

Methods: Using data from the Leuven College Surveys (Belgium), as part of the World Mental Health Surveys International College Student initiative, we crosssectionally assessed 12-month BPB and mental health problems among college firstyear students ( $n=4,889$; response rate $=73.2 \%$ ) at the beginning of the academic year. Objective measures of academic functioning (final grades, expressed in academic year percentage "AYP" [0-100\%] and academic failure) were obtained from administrative records at the end of the academic year. 
Results: Twelve-month prevalence of BPB was 7.6\% (7.3\%binge eating and $1.0 \%$ purging), with higher rates among females than males. Bivariate models showed an association between BPB and numerous mental health problems (ORs = 3.4-18.4). Multivariate models showed associations with non-suicidal self-injury, post-traumatic stress, internalizing/externalizing problems and suicidal ideation. After controlling for sociodemographic characteristics and comorbid mental health problems, BPB were still associated with lower AYP ( -4.1 to $-11.2 \%$ range) and elevated odds of academic year failure (ORs $=1.4-4.2)$.

Conclusions: BPB (especially binge eating) are relatively common and associated with mental health problems, comparatively low academic performance, and higher risk of academic failure among college first-year students. Further study is needed to examine the causal dynamics underlying these associations.

\section{KEYWORDS}

academic, binge eating, college students, comorbidity, eating disorders, purging

\section{1 | INTRODUCTION}

Binge eating and purging behaviors (BPB) are common in western countries (McBride, McManus, Thompson, Palmer, \& Brugha, 2013), with estimates for binge eating in the $4.2-11.2 \%$ range (more commonly reported by female than male respondents; ReichbornKjennerud et al., 2003) and 1.3-2.4\% for purging (with three times higher odds for women; Mitchison \& Mond, 2015). The incidence of BPB peaks in late adolescence (Lewinsohn, Striegel-Moore, \& Seeley, 2000; Sim, Lebow, \& Billings, 2013), with the transition from high school to college being a sensitive period for the occurrence of BPB (Compas, Wagner, Slavin, \& Vannatta, 1986; Levine \& Smolak, 1996; Slane, Klump, McGue, \& lacono, 2014; Yu et al., 2018).

BPB are associated with increased physical and mental health problems (Fairweather-Schmidt, Lee, \& Wade, 2015; Kärkkäinen, Mustelin, Raevuori, Kaprio, \& Keski-Rahkonen, 2018; Wade, Wilksch, \& Lee, 2012). However, most researchers have investigated associations with mental health problems-such as mood and anxiety disorders (Berg, Frazier, \& Sherr, 2009; Keski-Rahkonen \& Mustelin, 2016), substance use, post-traumatic stress, or personality disorders (Solmi, Hatch, Hotopf, Treasure, \& Micali, 2014; Woodside et al., 2001), suicidal thoughts and behaviors or non-suicidal self-injury (Eisenberg, Nicklett, Roeder, \& Kirz, 2011; Micali et al., 2015)-either in isolation, or in consideration of only a limited set of comorbidities. Given that these mental health problems frequently co-occur (Auerbach et al., 2016), it is unclear whether BPB are uniquely associated with specific mental health problems. In order to address this limitation, it is necessary to examine a large variety of mental health problems together in relation to BPB. In addition, given that BPB are common among emerging adults and that the vast majority of high school graduates enroll in college (UNESCO Institute for Statistics, 2015), it is surprising that the association between BPB and academic performance has rarely been investigated. To our knowledge, the only studies that assessed this association (Hoerr, Bokram, Lugo, Bivins, \& Keast, 2002; Yanover \& Thompson, 2008) found higher levels of subjectively perceived interference in academic functioning among students reporting eating disorder symptoms. However, these findings should be interpreted with caution because of the relatively low number of cases, the absence of assessments of comorbid disorders, which could be causing the academic impairment, and the use of selfreported measures of academic interference-all related to possible bias (Kuncel, Credé, \& Thomas, 2005). Hence, further work on this topic is needed to clarify whether BPB are associated with an objectively recorded lower academic performance and higher risk of failing the first-year students (Dalgard, Mykletun, Rognerud, Johansen, \& Zahl, 2007; Hooven, Snedker, \& Thompson, 2012; Jablonska et al., 2012). If this is the case, it is crucial to clarify whether this association remains significant if we control for sociodemographic confounders and the presence of mental health problems.

In order to address these limitations, we use data from the Leuven College Surveys, carried out in annual surveys of college during the academic years 2012-2013 and 2013-2014, as part of the WHO World Mental Health International College Student Initiative (WMHICS; http://www.hcp.med.harvard.edu/wmh/college_student_survey. php). The WMH-ICS aims to collect cross-national epidemiological information about mental health problems among college populations worldwide. Building upon these findings, the initiative will investigate the efficacy of various interventions promoting students' well-being, social integration, and academic functioning. The aim of this study is to investigate the prevalence of BPB in the past year, the associated mental health problems, the extent to which BPB were associated with objectively-assessed measures of academic performance (obtained from official university records at the end of the first year of college), and to test this association controlling for sociodemographic confounders and comorbidity. The setup is exploratory in nature, and, hence, hypotheses-generating instead of hypotheses-testing. Against 
this backdrop, we anticipated a prevalence rate of BPB in the 10-35\% range (Berg et al., 2009; Dakanalis et al., 2016; Lipson \& Sonneville, 2017). As only few studies investigated the associations between mental health problems and BPB in a multivariate context, no specific hypotheses were formulated regarding unique associations between both. In addition, this is the first study that investigates the association between BPB and objective academic performance, and so our approach is exploratory in nature. As previous studies found that certain sociodemographic characteristics and mental health problems were related to reduced academic performance (Auerbach et al., 2016; Bruffaerts et al., 2018; Kiekens et al., 2016; Mortier et al., 2015), we controlled for sociodemographic confounders and the presence of other mental health problems.

\section{2 | METHODS}

\section{$2.1 \mid$ Procedures}

As a part of the WMH-ICS, data were extracted from the Leuven College Surveys (Belgium), an ongoing web-based survey of KU Leuven college students. With over 40,000 students enrolled, KU Leuven represents Belgium's largest university. In 2012-2013 and 2013-2014, a total of 7,493 Dutch-speaking incoming students were eligible for inclusion at the start of the academic year (i.e., census sampling). Recruitment was structured in three phases and involved different strategies to achieve a higher response rate. In Phase 1, enrolled students received a letter inviting them to a free psycho-medical examination organized by the local student health center. During the checkup, the survey was administered. In phase two, nonrespondents were sent customized e-mails containing secured internet links to the survey. Phase 3 was identical to Phase 2, but included an additional incentive (i.e., a 20-euro store credit coupon). Each phase included reminders, which were sent to a maximum amount of eight contacts. The final sample consisted of 4,889 students, for an overall weighted response rate of $73.2 \%$ (adjusted for dropout rate during the academic year). The study's protocol was approved by the University Hospital Leuven Biomedical Ethical Board (B322201215611) and by the Belgian Commission for the Protection of Privacy (VT005053139).

\subsection{Measures}

\subsection{1 | Socio-demographic and college-related variables}

Socio-demographic characteristics were assessed at the beginning of the academic year and included gender (female vs. male), age (i.e., 18 years or younger vs. 19 years and older), nationality (i.e., Belgian vs. non-Belgian), family financial situation (i.e., easy vs. difficult: students were asked to evaluate their family financial situation as very easy, easy, fairly easy or fairly difficult, difficult, very difficult; responses were then dichotomized), parental level of education (i.e., high: both parents completed at least a bachelor's degree; mixed: only one completed a bachelor's degree; and low: neither completed a bachelor's degree), and family composition (i.e., separated/divorced vs. married parents). College-related variables included: secondary school type (i.e., general vs. nongeneral track), student status (i.e., full time vs. non-full time), and higher-level field of study (i.e., Biomedical sciences, Science and Technology, and Human Sciences).

\subsection{2 | Twelve-month binge eating and purging behaviors}

BPB were assessed at the beginning of the academic year using selective items, taken from the Mini International Neuropsychiatric Interview Screen (Lecrubier et al., 1997), evaluating pathological binge eating and pathological purging. The full measure investigates the presence of 17 different disorders and has a good inter-rater reliability (kappa coefficients ranging from 0.88 to 1.0 ) and test-retest reliability (kappa coefficients between 0.76 and 0.93). The items used for assessing the presence of BPB have shown high specificity (0.96) and reasonable sensitivity (0.63) with eating disorders. Students were asked: "Have you ever experienced times lasting 3 months or longer when you had eating binges at least twice a week; that is, your eating was out of control and you ate a very large amount of food over a short period of time (2 hr or less)?" and "Have you ever experienced times lasting 3 months or longer when you made yourself vomit or took laxatives or did other things to avoid gaining weight after binge eating?" Twelvemonth prevalence was scored positively if students indicated having experienced such a period in the 12 months prior to college entry.

\subsection{3 | Twelve-month mental health problems}

Mental health problems were assessed at the beginning of the academic year utilizing the Global Appraisal of Individual Needs Short Screener (GAIN-SS), a well-validated instrument for the screening of 12-month mental health problems in adolescent and adult populations (Dennis, Chan, \& Funk, 2006). This instrument, consisting of 20-items, is designed to identify groups of adolescents and young adults with a possible need for referral or treatment and to help with treatment planning and evaluation of progress (Dennis et al., 2006). The GAINSS is also accurate and useful in addressing mental health and substance abuse problems and has been validated among several different populations (e.g., Mortier et al., 2015; Sacks, Melnick, \& Grella, 2008; Shinn et al., 2007; Truman, Sharar, \& Pompe, 2011). It also has been used to screen for various mental health problems such as major depression, psychotic problems, substance abuse problems, and bipolar disorder (Rush, Castel, Brands, Toneatto, \& Veldhuizen, 2012; SAMHSA, 2015). The GAIN-SS scoring presents four sub-scales, addressing one mental health problem's subgroup: internalizing problems (depression, anxiety, insomnia, post-traumatic stress, and suicidality), externalizing problems (inattentiveness, hyperactivity, impulsivity, and conduct disorder), substance use and abuse 
(problematic use, substance abuse, and dependence), and crime/violence-related problems (interpersonal, property, and drug-related crimes). The instrument's subscales showed reasonable to good internal consistency (Cronbach $\alpha=0.65-0.81$ ), and a high correlation with the original corresponding subscales of the 60-120 min DSM-IV-TR based GAIN structured interview (Pearson $r=0.84-0.93$ ). Recommended cutoff scores for each problem are three or more positive symptoms. Although the GAIN-SS accurately detects mental health problems, it does not assess categorical mental health disorders.

We also assessed risk for other mental health problems. Screening for mania/hypomania and intermittent explosive disorder included two items from the screener section of the Composite International Diagnostic Interview, third version (CIDI-3.0; Kessler \& Üstün, 2004). Past year psychotic symptoms (i.e., hallucinations and delusions) included two items taken from the CIDI-3.0 Psychosis Screener (Haro et al., 2006). Non-suicidal self-injury was assessed with the corresponding item from the Self-Injurious Thoughts and Behaviors Interview (SITBI; Nock, Holmberg, Photos, \& Michel, 2007) that asked students "Did you ever do something to hurt yourself on purpose, without wanting to die (e.g., cutting yourself, hitting yourself, or burning yourself)?" The SITBI construct validity for Non-Suicidal Self Injury (NSSI) is good ( $\kappa=0.74$ ), with excellent inter-rater reliability and test-retest reliability after 6-month follow-up STB items were taken from the SITBI (Nock et al., 2007). For the purpose of this research, we included data regarding suicidal ideation ("Did you ever in your life have thoughts of killing yourself?"), with the latter being clearly differentiated from a passive death wish ("Did you ever wish you were dead or would go to sleep and never wake up?"). The construct validity of the SITBI is good to excellent in comparison to other instruments including the Kiddie Schedule for Affective Disorders and Schizophrenia (K-SADS-PL; $\kappa=0.48-0.65$ ) and the Beck Scale for Suicide Ideation $(\kappa=0.59)$. Also, inter-rater reliability and test-retest reliability are excellent $(\kappa=0.7-1.0$; Nock et al., 2007).

\subsection{4 | Academic performance}

Academic performance was obtained at the end of the academic year using two specific outcomes. First, academic year percentage (AYP) is the final grade percentage (range $0.0-100.0 \%$ ), as objectively calculated by the KU Leuven administration office. The AYP, mean result of all final course grades (in terms of percentages) obtained after the examination periods in June and September, is an expression of the academic achievement of the individual student in a given academic year. The AYP for each year is calculated after the completion of any retakes the following September. If students do not participate in an examination, the grade obtained for that particular course is zero. Second, we also use cumulative study efficiency (CSE) as a measure of academic performance. CSE is a percentage that reflects the relation between the number of credits a student has passed throughout the year within a program and the number of credits that student has taken within that program. Thus, CSE provides an indication of course progress; first-year students with CSE < 30\% are not allowed to continue with their academic program, and therefore fail their first year of college. Based on the CSE scores we received by the KU
Leuven administration office, students were grouped into two groups, those with CSE $\geq 30 \%$ and those with CSE $<30 \%$.

\section{3 | Statistical analyses}

Appropriate missing data strategies were used to ensure that findings were representative of the entire student population. Nonresponse propensity weighting was performed to account for potential differences between survey respondents and nonrespondents on the sociodemographic and college-related variables included in the study, and multivariate imputation by chained equations was used to adjust for within-survey item nonresponse (van Buuren, 2007). Using the package mice in R (Buuren \& Groothuis-Oudshoorn, 2011), the final data consisted of 100 imputed datasets obtained after 100 iterations. Descriptive statistics and prevalence estimates were reported as weighted numbers (n), and weighted proportions (\%) with associated standard errors. Crosssectional associations between 12-month BPB and mental health problems were evaluated using bivariate and multivariate logistic regression models and reported as odds ratios and associated $95 \%$ confidence intervals. Based on multivariate equations, including relevant sociodemographic (as derived in preliminary analyses; see Table S1) and presence of 12-month comorbidity, we evaluated the prospective association between BPB and academic performance in two ways. First, we used linear regression analyses to examine whether 12-month BPB were associated with significantly lower AYP (0-100\%). Second, we used logistic regression analyses to examine whether students with 12-month BPB had significantly elevated odds of having to end their study program due to insufficient study progress (i.e., CSE $<30 \%$ ). Finally, we also determined the Population Attributable Risk Proportion (PARP) of 12-month BPB by calculating what proportion of students failing the academic year may have been prevented, if it were possible to prevent or treat each case of 12 -month BPB, assuming a causal association. All analyses were performed with SAS (version 9.4) and R (version 3.5.1).

\section{3 | RESULTS}

\section{1 | Sample description}

Sample characteristics are presented in Table 1 . The sample consisted of 4,889 first-year students, (55.4\% females) with an average age of 18.4 $(S E=1.1)$. Mean AYP was $50.0(S D=18.1 ; S E=0.3)$ with $24.1 \%(S E=0.6)$ of the students under the $30.0 \%$ CSE cutoff for passing the academic year. These estimates are comparable to the entire population of students at $\mathrm{KU}$ Leuven (mean AYP = 48.5\%; SD = 18.5; CSE < 30\% =26.8\%).

\section{2 | Twelve-month binge eating and purging behaviors}

BPB in the past year were reported by $7.6 \%$ (SE $=0.4$ ) of first-year students, with higher estimates for binge eating $(7.3 \%$ [SE $=0.4])$ than 
TAB LE 1 Sociodemographic and college-related characteristics of the total sample $(n=4,889)$

\begin{tabular}{|c|c|c|c|}
\hline Sociodemographic variables & $w(n)$ & w (\%) & SE \\
\hline Sex (female) & 2,709 & 55.4 & 0.7 \\
\hline Age $>18$ years & 1,261 & 25.8 & 0.7 \\
\hline Belgian nationality & 4,531 & 92.7 & 0.4 \\
\hline Parents' financial situation difficult & 862 & 17.6 & 0.6 \\
\hline \multicolumn{4}{|l|}{ Parental educational level ${ }^{a}$} \\
\hline Both parents high education & 2,854 & 58.4 & 0.8 \\
\hline One parent high education & 1,205 & 24.6 & 0.7 \\
\hline Neither parents high education & 830 & 17.0 & 0.6 \\
\hline Non-married parents ${ }^{\mathrm{b}}$ & 1,070 & 21.9 & 0.7 \\
\hline \multicolumn{4}{|l|}{ College-related variables } \\
\hline Fulltime student & 4,611 & 94.3 & 0.3 \\
\hline \multicolumn{4}{|l|}{ Area of enrolment } \\
\hline Human sciences & 2,353 & 48.1 & 0.7 \\
\hline Science and technology & 1,387 & 28.4 & 0.6 \\
\hline Biomedical sciences & 1,149 & 23.5 & 0.6 \\
\hline General secondary school track & 4,557 & 93.2 & 0.4 \\
\hline \multicolumn{4}{|l|}{ Academic performance } \\
\hline \multirow[t]{2}{*}{ Cumulative study efficiency (CSE) $<30 \%$} & 1,179 & 24.1 & 0.6 \\
\hline & Mean & $S D$ & SE \\
\hline Academic year percentage (AYP) & 50.0 & 18.1 & 0.3 \\
\hline
\end{tabular}

Abbreviations: $w(n)$, weighted number of cases; $w(\%)$, weighted percentage of sample; SE, standard error; SD, standard deviation. ${ }^{a} H i g h$ education level was defined as holding at least a bachelor's degree. ${ }^{b}$ Defined as parents divorced or separated.

purging (1.0\% [SE = 0.2]). Binge eating infrequently co-occurred with purging: only $10.1 \%$ ( $S E=1.8$ ) of those who reported binge eating in the past year also reported purging. Conversely, 12-month purging was strongly associated with binge eating, with 70.6\% (SE $=7.1$ ) of students with purging behaviors also reporting binge eating. Purging only was rare and present in only $0.3 \%$ (SE $=0.1$ ) of students; making comparisons using this specific group not possible in further analyses. In comparison to men, being a woman was significantly associated with $\mathrm{BPB}$, with elevated odds ratios of $1.7(95 \% \mathrm{Cl}=1.3-2.21)$ for binge eating (i.e., 8.9 vs. $5.4 \%)$ and $3.8(95 \% \mathrm{Cl}=1.6-8.9)$ for purging (i.e., 1.6 vs. $0.4 \%$ ).

\section{3 | Comorbidity patterns between binge eating and purging behaviors and mental health problems}

Table 2 shows bivariate associations between 12-month BPB and mental health problems. Three findings stand out. First, the binge eating only group showed a high rate of comorbid mental health problems compared to the group without BPB (ORs in the 3.4-6.6 range; median OR = 4.4). Second, compared to the group without BPB, the comorbid binge eating, and purging group showed the highest prevalence of mental health problems, with elevated odds varying from 6.8 for intermittent explosive disorder and 18.4 for NSSI. Third, we found a significant linear association between BPB (for both the binge eating only and the both binge eating and purging groups) and the total number of comorbid mental health problems.

Table 3 presents the multivariate analyses of BPB comorbidity patterns. Binge eating only was significantly associated with 5 of 8 mental health problems (ORs in the 1.7-2.4 range; median $\mathrm{OR}=1.8$ ), with elevated odds for both internalizing and externalizing emotional problems. Students reporting comorbid binge eating and purging also were significantly more likely to engage in 12-month NSSI when compared to students reporting no BPB $(O R=3.9)$ and students reporting only binge eating or purging (i.e., the single BPB group; $O R=3.2$ ).

\section{4 | Associations between 12-month BPB and academic functioning}

The association between BPB and both AYP and CSE was investigated in bivariate and multivariate models (Table 4). Even after controlling for relevant sociodemographic confounders (see Table S1) and presence of comorbid mental health problems, we observed a significant negative association between BPB and academic functioning. Both binge eating ( $\beta=-4.1 \%$ ) and purging ( $\beta=-11.2 \%$ ), were associated with lower AYP, as well as higher odds of 1.4 and 4.3 for failing the first year of college. The PARP calculations indicate that up to $3.9 \%$ of all first-year students failing the academic year may be preventable, if it were possible to prevent or treat each case of 12-month BPB, assuming a causal association between BPB and academic performance.

\section{4 | DISCUSSION}

This is the first study in a representative sample of college first year students that investigated the prevalence of BPB and associated psychiatric comorbidities with objectively recorded indicators of academic functioning. These elements contribute substantially to prior research in the fields of disordered eating and college mental health. The major findings are that BPB (especially binge eating) are relatively common behaviors in first-year college students and are associated with a variety of mental health problems, as well as comparatively low academic functioning.

The 12-month prevalence of BPB (i.e., 7.6\%) fall in the lower range of previous findings in college population, for both binging (Dakanalis et al., 2016; Eisenberg et al., 2011) and purging (Mitchison, Hay, Slewa-Younan, \& Mond, 2014; Tomori \& Rus-Makovec, 2000). Possible explanations are the high specificity of the items usedprevious studies used a much broader definition of BPB (Lipson \& Sonneville, 2017)-and cultural differences in eating habits across countries and continents (Mitchison, Touyz, Gonzalez-Chica, Stocks, \& Hay, 2017). Consistent with previous research, female students reported binge eating and purging at two- and five-times higher rates than males. Interestingly, male students reported a similarly higher risk 
TABLE 2 Bivariate associations between 12-month binge eating, purging, and comorbid mental health problems

\begin{tabular}{|c|c|c|c|c|c|c|}
\hline $\begin{array}{l}\text { 12-month mental health } \\
\text { problems }\end{array}$ & \multicolumn{3}{|c|}{ Prevalence $^{a}$} & $\begin{array}{l}\text { Binge eating only vs. no BPB } \\
\text { (referent group) } \\
\text { OR }(95 \% \mathrm{Cl})\end{array}$ & $\begin{array}{l}\text { Comorbid BPB vs. no BPB } \\
\text { (referent group) } \\
\text { OR }(95 \% \mathrm{Cl})\end{array}$ & $\begin{array}{l}\text { Comorbid BPB vs. single BPB } \\
\text { (referent group) } \\
\text { OR }(95 \% \mathrm{Cl})\end{array}$ \\
\hline Internalizing problems & 977 & 21.6 & 0.7 & $5.0(3.9 ; 6.4)$ & $9.3(4.2 ; 20.2)$ & $1.9(0.9 ; 4.3)$ \\
\hline Externalizing problems & 738 & 16.3 & 0.6 & $4.1(3.2 ; 5.3)$ & $8.2(4.0 ; 16.8)$ & $2.0(1.0 ; 4.3)$ \\
\hline $\begin{array}{l}\text { Substance use } \\
\text { problems }\end{array}$ & 204 & 4.5 & 0.4 & $3.4(2.4 ; 5.0)$ & $7.7(3.5 ; 16.7)$ & $2.2(1.0 ; 5.1)$ \\
\hline $\begin{array}{l}\text { Positive screen broad } \\
\text { mania }\end{array}$ & 245 & 5.4 & 0.4 & $6.6(4.9 ; 9.0)$ & $11.9(5.9 ; 24.3)$ & $1.8(0.9 ; 3.9)$ \\
\hline Positive screen PTSD & 610 & 13.5 & 0.6 & $5.4(4.1 ; 7.0)$ & $11.6(5.6 ; 24.0)$ & $2.2(1.0 ; 4.8)$ \\
\hline $\begin{array}{r}\text { Psychotic life } \\
\text { experience }\end{array}$ & 135 & 3.0 & 0.3 & $3.4(2.1 ; 5.3)$ & $11.1(4.9 ; 25.0)$ & $3.2(1.3 ; 8.0)$ \\
\hline $\begin{array}{l}\text { Any comorbid mental } \\
\text { health problem }\end{array}$ & 1,815 & 40.2 & 0.8 & $6.6(4.8 ; 9.1)$ & $11.8(3.9 ; 35.8)$ & $1.9(0.6 ; 5.9)$ \\
\hline \multicolumn{7}{|l|}{$\begin{array}{l}\text { No. comorbid mental } \\
\text { health problems }\end{array}$} \\
\hline None & 2,701 & 59.8 & 0.8 & Ref & Ref & Ref \\
\hline 1 & 908 & 20.1 & 0.7 & $2.8(1.8 ; 4.2)$ & $2.6(0.5 ; 12.2)$ & $0.9(0.2 ; 4.6)$ \\
\hline 2 & 507 & 11.2 & 0.5 & $5.1(3.4 ; 7.7)$ & $5.2(1.2 ; 23.3)$ & $1.1(0.2 ; 5.0)$ \\
\hline 3 & 213 & 4.7 & 0.4 & $12.7(8.3 ; 19.4)$ & $14.9(3.6 ; 62.8)$ & $1.2(0.3 ; 5.5)$ \\
\hline 4 or more & 187 & 4.1 & 0.3 & $22.8(15.2 ; 34.0)$ & $74.9(23.8 ; 235.9)$ & $3.5(1.1 ; 11.5)$ \\
\hline
\end{tabular}

Note: Significant associations are shown in bold.

Abbreviations: $w(n)$, weighted number of cases, w(\%), weighted percentage; SE, standard error; BPB, binge eating and pruging behaviors; OR, odds ratio, 95\% Cl, 95\% confidence interval; IED, intermittent explosive disorder; PTSD, post-traumatic stress disorder; Ref, reference group.

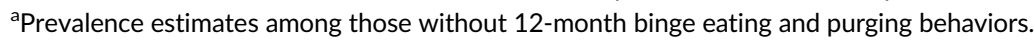

${ }^{b}$ Pooled estimate of 100 Cochran-Armitage linear trend tests. Bivariate associations are based on separate models for each row, with the variable in the row as predictor. Binge eating only refers to students who report binge eating in the past 12-months without purging $(n=322)$. Comorbid BPB refers to students who report both 12-month binge eating and purging $(n=36)$. Single BPB refers to students with either 12 -month binge eating or purging, but not both $(n=337)$. No BPB refers to students without 12 -month binge eating and purging $(n=4,516)$.

for binge drinking (Wilsnack, Wilsnack, Gmel, \& Kantor, 2017), which might be an indication of underlying gender liabilities with different clinical manifestations of an underlying psychological factor.

The current findings provide further evidence for a robust link between BPB and a range of mental health problems, including both internalizing and externalizing emotional problems. These associations may reflect a shared underlying vulnerability. BPB may also represent a coping mechanism for anxiety, depression, or PTSD-related traumatic memories (Palmisano et al., 2018). Alternatively, BPB may also increase risk for onsets of other mental health problems (e.g., Riley, Davis, Combs, Jordan, \& Smith, 2016). In addition, the comorbidity with NSSI/suicidal behaviors has been reported in eating disorder patients, as these behaviors may be functionally equivalent within the self-harming spectrum (Claes \& Muehlenkamp, 2014; Fox et al., 2019). Taken together, our data are consistent with the thought that BPB represent a behavioral marker of psychopathological distress among incoming college students. In addition, our results are in line with previous research showing that binge eating is as strongly associated with adverse outcomes as the combination of both binge eating and purging (Kessler et al., 2013), therefore further validating the decision of DSM-5 to designate a specific binge-eating disorder as distinct from bulimia nervosa.

Students who engaged in BPB in the past year had, on average, a decrease of $4.1-11.2 \%$ in their AYP compared to those without BPB. That means that, on average, a student who functions on an academic level in the 50th percentile will drop to the 25th-35th percentile in the presence of BPB (Bruffaerts et al., 2018). We also found that a student with binge eating had 1.4 higher odds of failing the first year than did other students with comparable scores on all other measured predictors. Those with purging are more than four times more likely to fail their academic year. On balance, BPB are associated with lower academic functioning compared to other mental health problems. Previous studies have shown prospectively lower academic functioning in association with anxiety, depression, and other types of internalizing 
TAB LE 3 Multivariate associations between 12-month binge eating and purging behaviors and comorbid mental health problems

\begin{tabular}{|c|c|c|c|}
\hline & $\begin{array}{l}\text { Binge eating only vs. } \\
\text { no BPB (referent group) }\end{array}$ & $\begin{array}{l}\text { Comorbid BPB vs. } \\
\text { no BPB (referent group) }\end{array}$ & $\begin{array}{l}\text { Comorbid BPB vs. } \\
\text { single BPB (referent group) }\end{array}$ \\
\hline 12-month mental health problems & OR $(95 \% \mathrm{Cl})$ & OR $(95 \% \mathrm{Cl})$ & OR $(95 \% \mathrm{Cl})$ \\
\hline Externalizing problems & $1.8(1.3 ; 2.7)$ & $2.2(0.9 ; 5.4)$ & $1.4(0.5 ; 3.5)$ \\
\hline Substance use problems & $1.5(0.9 ; 2.4)$ & $2.3(0.9 ; 6.3)$ & $1.7(0.6 ; 4.9)$ \\
\hline Positive screen PTSD & $1.7(1.1 ; 2.6)$ & $1.8(0.6 ; 4.9)$ & $1.7(0.6 ; 4.6)$ \\
\hline Psychotic life experiences & $1.0(0.6 ; 1.8)$ & $1.8(0.7 ; 4.9)$ & $1.9(0.7 ; 5.3)$ \\
\hline Non-suicidal self-injury & $1.2(0.6 ; 2.1)$ & $3.9(1.4 ; 11.3)$ & $3.2(1.0 ; 9.6)$ \\
\hline Suicide ideation & $1.7(1.0 ; 2.8)$ & $1.4(0.5 ; 4.1)$ & $0.8(0.2 ; 2.6)$ \\
\hline 3 & $2.1(0.9 ; 4.6)$ & $2.4(0.4 ; 14.9)$ & $0.7(0.1 ; 4.9)$ \\
\hline 4 or more & $1.7(0.5 ; 5.3)$ & $3.7(0.4 ; 37.0)$ & $1.1(0.1 ; 11.8)$ \\
\hline$\chi^{2}(p \text {-value })^{a}$ & $1.5(.220)$ & $1.2(.283)$ & $0.2(.649)$ \\
\hline
\end{tabular}

Note: Significant associations are shown in bold.

Abbreviations: BPB, binge eating and pruging behaviors; OR, odds ratio, 95\% Cl, 95\% confidence interval; IED, intermittent explosive disorder; PTSD, posttraumatic stress disorder; Ref, reference group.

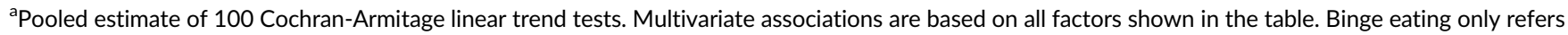
to students who report binge eating in the past 12-months without purging $(n=322)$. Comorbid BPB refers to students who report both 12 -month binge eating and purging $(n=36)$. Single BPB refers to students with either 12-month binge eating or purging, but not both $(n=337)$. No BPB refers to students without 12-month binge eating and purging $(n=4,516)$.

emotional problems of $1.2-2.9 \%$ of the academic percentage (Eisenberg et al., 2011; Hysenbegasi, Hass, \& Rowland, 2005). Other reported a lower AYP of $4.7 \%$ in students with externalizing mental health problems (Bruffaerts et al., 2018), 3.6-7.9\% in those with suicidal thoughts and behaviors (Mortier et al., 2015) and 5.9\% in those engaging in NSSI (Kiekens et al., 2016). In contrast to broader constructs like anxiety and depression, BPB are specific behavioral manifestations. It is therefore striking that, even after controlling for comorbidities (together with other important confounders like gender), BPB were still associated with academic impairment. The high prevalence of BPB, as well as its significant impact on academic functioning, call to the need for a better understanding of these common behaviors among college students, as they may add to long-term consequences for both individuals, and society. Our findings suggest that timely, effective interventions for BPB may prevent up to $3.9 \%$ of first-year academic failures (i.e., 78 students in this study).

\subsection{Limitations and future directions}

Several limitations deserve attention in interpreting the results of this study. First, although a response rate of $73 \%$ is strong, residual nonresponse bias might have affected our findings. To address this, we applied state-of-the-art missing data handling techniques. Yet, when considering the local nature of our data, further research is needed to evaluate the generalizability of our findings. Indeed, food and eating habits may vary significantly across countries, potentially impacting the prevalence of BPB and the associated psychological burden (Mitchison et al., 2017). Second, our study was based on well-validated items rather than clinical interviews. For instance, the wording of the item assessing purging not only mentions whether students vomited or took laxatives, but also questions whether they did other things to avoid gaining weight. Some students may have interpreted the latter as also including behaviors, such as fasting or exercising, that are not considered purging. Consequently, the true prevalence of purging might be even lower than the one reported here. Relatedly, it is unclear what proportion of students with 12-month BPB of our sample would also meet full threshold disorder criteria. Emerging evidence shows that $10.5 \%$ of college students engaging in disordered eating behaviors also fulfill the diagnostic criteria for an eating disorder (Sonneville \& Lipson, 2018). An important next step will therefore be to clarify to what extent solely engaging in BPB is related to higher risk of comorbidity and academic failure. Further, it is probably unlikely that the prospective association between BPB and academic performance is a direct one. Future research is needed beyond this initial investigation to evaluate the generalizability of these findings and clarify the causal dynamics underlying these associations. Indeed, BPB interact with 
TAB LE 4 Prediction of 12-month binge eating and purging behaviors on academic year percentage and cumulative study efficiency

\begin{tabular}{|c|c|c|c|c|}
\hline & \multicolumn{2}{|c|}{ Academic year percentage } & \multicolumn{2}{|c|}{ Cumulative study efficiency $<30 \%$} \\
\hline \multicolumn{5}{|l|}{ 12-month binge eating and purging behaviors } \\
\hline Binge eating (yes versus no) & $-6.5(-8.7 ;-4.2)$ & $-4.1(-6.2 ;-1.9)$ & $1.7(1.3 ; 2.3)$ & $1.4(1.1 ; 1.9)$ \\
\hline Comorbid BPB & $-13.5(-20.3 ;-6.7)$ & $7.1(-4.5 ; 18.8)$ & $2.8(1.3 ; 5.7)$ & $0.3(0.1 ; 1.2)$ \\
\hline \multicolumn{5}{|l|}{ Covariates } \\
\hline Sex (female) & - & $2.1(1.1 ; 3.1)$ & - & $0.8(0.7 ; 0.9)$ \\
\hline Age $>18$ years & - & $-6.2(-7.4 ;-5.1)$ & - & $2.0(1.7 ; 2.3)$ \\
\hline Belgian nationality & - & $3.4(1.3 ; 5.6)$ & - & $0.7(0.5 ; 0.9)$ \\
\hline One parent high education & - & $-3.3(-4.5 ;-2.1)$ & - & $1.4(1.2 ; 1.7)$ \\
\hline Neither parents high education & - & $-5.0(-6.4 ;-3.5)$ & - & $1.7(1.4 ; 2.1)$ \\
\hline Non-intact family composition ${ }^{c}$ & - & $-2.1(-3.4 ;-0.8)$ & - & - \\
\hline \multicolumn{5}{|l|}{ Area of enrolment } \\
\hline Human sciences & - & Ref & - & Ref \\
\hline Science and technology & - & $3.4(2.2 ; 4.6)$ & - & $0.7(0.6 ; 0.8)$ \\
\hline Biomedical sciences & - & $1.0(-0.2 ; 2.2)$ & - & $0.9(0.8 ; 1.1)$ \\
\hline General secondary school track & - & $14.7(12.7 ; 16.7)$ & - & $0.2(0.2 ; 0.3)$ \\
\hline
\end{tabular}

Note: Significant associations are shown in bold. The combined effect of comorbid BPB in the joint multivariate models needs to be interpreted by summing/multiplying the effects of the indicator variables binge eating, purging, and comorbid BPB in the prediction of academic year percentage (linear model)/cumulative study efficiency below $30 \%$ (logistic model). For example, the combined effect of comorbid BPB $(=-4.1-11.2+7.1)$ in the prediction of academic year percentage equals a reduction of $8.2 \%$, holding all other predictors equal. This is an example of a subadditive effect in which the joint effect of two conditions is less than the sum of their individual effects.

Abbreviations: $\mathrm{B}$, unstandardized beta coefficient, OR, odds ratio, $95 \% \mathrm{Cl}, 95 \%$ confidence interval, Ref, reference group.

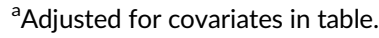

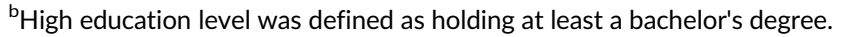

'Defined as parents divorced or separated. Academic year percentage ranges between 0 and $100 \%$.

multiple variables in complex models. Studies with larger samples should build upon these findings and test more complex models-for example, larger sets of specific mental health problems, familial or relational variables in the prediction of academic performance, or a potential moderating role of gender and weight in the relation between BPB, mental health problems, and academic functioning. Finally, longitudinal studies are needed to investigate the predictive role of BPB on long-term mental health and academic outcomes.

These limitations notwithstanding, the current study makes significant advances in the field of mental health in college students by demonstrating, for the first time, that the presence of 12-month BPB are objectively associated with comparatively low academic performance, as well as higher risk of academic failure among college first year students. Awaiting further research, we provide preliminary evidence that the presence of 12-month BPB may be useful behavioral markers to identify vulnerable students with increased mental health and academic difficulties in the first year of college.

\section{ACKNOWLEDGMENTS}

The survey was carried out in conjunction with the WHO World Mental Health International College Surveys Initiative (WHO WMH-ICS). We thank the staff of the WMH Data Analysis Coordination Centre for assistance with instrumentation and data analysis. A complete list of all within-country and cross-national WMH-ICS publications can be found at http://www.hcp.med.harvard.edu/wmh/

\section{DATA AVAILABILITY STATEMENT}

Data will be made available upon explicit request.

\section{ORCID}

Riccardo Serra (D) https://orcid.org/0000-0003-4105-5078

\section{REFERENCES}

Auerbach, R. P., Alonso, J. L., Axinn, W. G., Cuijpers, P., Ebert, D. D., Green, J. G., ... Bruffaerts, R. (2016). Mental disorders among college 
students in the World Health Organization world mental health surveys. Psychological Medicine, 46(14), 2955-2970. https://doi.org/10. 1017/S0033291716001665

Berg, K. C., Frazier, P., \& Sherr, L. (2009). Change in eating disorder attitudes and behavior in college women: Prevalence and predictors. Eating Behaviors, 10(3), 137-142. https://doi.org/10.1016/j.eatbeh.2009.03.003

Bruffaerts, R., Mortier, P., Kiekens, G., Auerbach, R. P., Cuijpers, P., Demyttenaere, K., ... Kessler, R. C. (2018). Mental health problems in college freshmen: Prevalence and academic functioning. Journal of Affective Disorders, 225, 97-103. https://doi.org/10.1016/j.jad.2017. 07.044

Buuren, S. V., \& Groothuis-Oudshoorn, K. (2011). Mice: Multivariate imputation by chained equations in R. Journal of Statistical Software, 45(3), 1-68. https://doi.org/10.18637/jss.v045.i03

Claes, L., \& Muehlenkamp, J. J. (2014). Non-suicidal self-injury in eating disorders: Advancementes in Etiology and treatment. Heidelberg: Springer.

Compas, B. E., Wagner, B. M., Slavin, L. A., \& Vannatta, K. (1986). A prospective study of life events, social support, and psychological symptomatology during the transition from high school to college. American Journal of Community Psychology, 14(3), 241-257. https://doi.org/10. 1007/BF00911173

Dakanalis, A., Timko, A., Serino, S., Riva, G., Clerici, M., \& Carrà, G. (2016). Prospective psychosocial predictors of onset and cessation of eating pathology amongst college women. European Eating Disorders Review, 24(3), 251-256. https://doi.org/10.1002/erv.2433

Dalgard, O. S., Mykletun, A., Rognerud, M. A., Johansen, R., \& Zahl, P. H. (2007). Education, sense of mastery and mental health: results from a nation wide health monitoring study in Norway. 7(1). https://doi.org/ 10.1186/1471-244X-7-20

Dennis, M. L., Chan, Y. F., \& Funk, R. R. (2006). Development and validation of the GAIN short screener (GSS) for internalizing, externalizing and substance use disorders and crime/violence problems among adolescents and adults. American Journal on Addictions, 15(s1), s80-s91. https://doi.org/10.1080/10550490601006055

Eisenberg, D., Nicklett, E. J., Roeder, K., \& Kirz, N. E. (2011). Eating disorder symptoms among college students: Prevalence, persistence, correlates, and treatment-seeking. Journal of American College Health, 59(8), 700-707. https://doi.org/10.1080/07448481.2010.546461

Fairweather-Schmidt, A. K., Lee, C., \& Wade, T. D. (2015). A longitudinal study of Midage women with indicators of disordered eating. Developmental Psychology, 51(5), 722-729. https://doi.org/10.1037/dev0000011

Fox, K., Wang, S., Boccagno, C., Haynos, A., Kleiman, E., \& Hooley, J. (2019). Comparing self-harming intentions underlying eating disordered behaviors and NSSI: Evidence that distinctions are less clear than assumed. International Journal of Eating Disorders., 52, 564-575. https://doi.org/10.1002/eat.23041

Haro, J. M., Arbabzadeh-Bouchez, S., Brugha, T. S., De Girolamo, G., Guyer, M. E., Jin, R., ... Kessler, R. C. (2006). Concordance of the composite international diagnostic interview version 3.0 (CIDI 3.0) with standardized clinical assessments in the WHO world mental health surveys. International Journal of Methods in Psychiatric Research, 15(4), 167-180. https://doi.org/10.1002/mpr.196

Hoerr, S., Bokram, R., Lugo, B., Bivins, T., \& Keast, D. (2002). Risk for disordered eating relates to both gender and ethnicity for college students. Journal of the American College of Nutrition, 21(4), 307-314. https:// doi.org/10.1080/07315724.2002.10719228

Hooven, C., Snedker, K. A., \& Thompson, E. A. (2012). Suicide risk at young adulthood: Continuities and discontinuities from adolescence. Youth \& Society, 44(4), 524-547. https://doi.org/10.1177/ $0044118 \times 11407526$

Hysenbegasi, A., Hass, S. L., \& Rowland, C. R. (2005). The impact of depression on the academic productivity of university students. The Journal of Mental Health Policy and Economics, 8(3), 145-151.
Jablonska, B., Lindblad, F., Östberg, V., Lindberg, L., Rasmussen, F., \& Hjern, A. (2012). A national cohort study of parental socioeconomic status and non-fatal suicidal behaviour-the mediating role of school performance. BMC Public Health, 12(1), 17. https://doi.org/10.1186/ 1471-2458-12-17

Kärkkäinen, U., Mustelin, L., Raevuori, A., Kaprio, J., \& Keski-Rahkonen, A. (2018). Do disordered eating behaviours have long-term health-related consequences? European Eating Disorders Review, 26(1), 22-28. https://doi.org/10.1002/erv.2568

Keski-Rahkonen, A., \& Mustelin, L. (2016). Epidemiology of eating disorders in Europe: Prevalence, incidence, comorbidity, course, consequences, and risk factors. Current Opinion in Psychiatry, 29(6), 340-345. https://doi.org/10.1097/YCO.0000000000000278

Kessler, R., Berglund, P., Chiu, W., Deitz, A., Hudson, J., Shahly, V., ... Xavier, M. (2013). The prevalence and correlates of binge eating disorder in the World Health Organization world mental health surveys. Biological Psychiatry, 73(9), 904-914. https://doi.org/10.1016/j. biopsych.2012.11.020

Kessler, R., \& Üstün, T. B. (2004). The world mental health (WMH) survey initiative version of the World Health Organization (WHO) composite international diagnostic interview (CIDI). International Journal of Methods in Psychiatric Research, 13(2), 93-121. https://doi.org/10. 1002/mpr.168

Kiekens, G., Claes, L., Demyttenaere, K., Auerbach, R. P., Green, J. G., Kessler, R. C., ... Bruffaerts, R. (2016). Lifetime and 12-month nonsuicidal self-injury and academic performance in college freshmen. Suicide and Life-Threatening Behavior, 46(5), 563-576. https://doi.org/10. 1111/sltb.12237

Kuncel, N. R., Credé, M., \& Thomas, L. L. (2005). The validity of selfreported grade point averages, class ranks, and test scores: A metaanalysis and review of the literature. Review of Educational Research, 75(1), 63-82. https://doi.org/10.3102/00346543075001063

Lecrubier, Y., Sheehan, D. V., Weiller, E., Amorim, P., Bonora, I., Harnett Sheehan, K., ... Dunbar, G. (1997). The MINI international neuropsychiatric interview (MINI). A short diagnostic structured interview: Reliability and validity according to the CIDI. European Psychiatry, 12(5), 224-231. https://doi.org/10.1016/S0924-9338(97)83296-8

Levine, M. P., \& Smolak, L. (1996). Media as a context for the development of disordered eating. In The developmental psychopathology of eating disorders (pp. 235-257). Hillsdale, NJ: Lawrence erlbaum associates.

Lewinsohn, P. M., Striegel-Moore, R. H., \& Seeley, J. R. (2000). Epidemiology and natural course of eating disorders in young women from adolescence to young adulthood. Journal of the American Academy of Child \& Adolescent Psychiatry, 39(10), 1284-1292. https://doi.org/10. 1097/00004583-200010000-00016

Lipson, S., \& Sonneville, K. (2017). Eating disorder symptoms among undergraduate and graduate students at 12 U.S. colleges and universities. Eating Behaviors, 24, 81-88. https://doi.org/10.1016/j.eatbeh. 2016.12.003

McBride, O., McManus, S., Thompson, J., Palmer, R., \& Brugha, T. (2013). Profiling disordered eating patterns and body mass index (BMI) in the English general population. Social Psychiatry and Psychiatric Epidemiology, 48(5), 783-793. https://doi.org/10.1007/s00127-012-0613-7

Micali, N., Solmi, F., Horton, N. J., Crosby, R. D., Eddy, K. T., Calzo, J. P., ... Field, A. E. (2015). Adolescent eating disorders predict psychiatric, high-risk Behaviors and weight outcomes in young adulthood. Journal of the American Academy of Child \& Adolescent Psychiatry, 54(8), 652-659.e651. https://doi.org/10.1016/j.jaac.2015.05.009

Mitchison, D., Hay, P., Slewa-Younan, S., \& Mond, J. (2014). The changing demographic profile of eating disorder behaviors in the community. BMC Public Health, 14(1), 943. https://doi.org/10.1186/1471-245814-943

Mitchison, D., Touyz, S., Gonzalez-Chica, D. A., Stocks, N., \& Hay, P. (2017). How abnormal is binge eating? 18-year time trends in 
population prevalence and burden. Acta Psychiatrica Scandinavica, 136 (2), 147-155. https://doi.org/10.1111/acps.12735

Mitchison, D., \& Mond, J. (2015). Epidemiology of eating disorders, eating disordered behaviour, and body image disturbance in males: A narrative review. Journal of Eating Disorders, 3(1), 20. https://doi.org/10. 1186/s40337-015-0058-y

Mortier, P., Demyttenaere, K., Auerbach, R. P., Green, J. G., Kessler, R. C., Kiekens, G., ... Bruffaerts, R. (2015). The impact of lifetime suicidality on academic performance in college freshmen. Journal of Affective Disorders, 186, 254-260. https://doi.org/10.1016/j.jad.2015.07.030

Nock, M. K., Holmberg, E. B., Photos, V. I., \& Michel, B. D. (2007). Selfinjurious thoughts and Behaviors interview: Development, reliability, and validity in an adolescent sample. Psychological Assessment, 19(3), 309-317. https://doi.org/10.1037/1040-3590.19.3.309

Palmisano, G. L., Innamorati, M., Susca, G., Traetta, D., Sarracino, D., \& Vanderlinden, J. (2018). Childhood traumatic experiences and dissociative phenomena in eating disorders: Level and association with the severity of binge eating symptoms. Journal of Trauma \& Dissociation, 19(1), 88-107. https://doi.org/10.1080/15299732.2017.1304490

Reichborn-Kjennerud, T., Bulik, C., Kendler, K., Roysamb, E., Maes, H., Tambs, K., \& Harris, J. (2003). Gender differences in binge-eating: A population-based twin study. Acta Psychiatrica Scandinavica, 108(3), 196-202. https://doi.org/10.1034/j.1600-0447.2003.00106.x

Riley, E. N., Davis, H. A., Combs, J. L., Jordan, C. E., \& Smith, G. T. (2016). Nonsuicidal self-injury as a risk factor for purging onset: Negatively reinforced behaviours that reduce emotional distress. European Eating Disorders Review, 24(1), 78-82. https://doi.org/10.1002/erv.2407

Rush, B., Castel, S., Brands, B., Toneatto, T., \& Veldhuizen, S. (2012). Validation and comparison of diagnostic accuracy of four screening tools for mental disorders in people seeking treatment for substance use disorders. Journal of Substance Abuse Treatment, 44(4), 375-383. https://doi.org/10.1016/j.jsat.2012.08.221

Sacks, S., Melnick, G., \& Grella, C. E. (2008). Introduction to this issue: Studies of co-occurring disorders in the criminal justice system. Behavioral Sciences \& the Law, 26(4), 347-349. https://doi.org/10.1002/ bsl.833

Shinn, M., Gottlieb, J., Wett, J. L., Bahl, A., Cohen, A., \& Baron Ellis, D. (2007). Predictors of homelessness among older adults in new York City: Disability, economic, human and social capital and stressful events. Journal of Health Psychology, 12(5), 696-708. https://doi.org/ 10.1177/1359105307080581

Sim, L. A., Lebow, J., \& Billings, M. (2013). Eating disorders in adolescents with a history of obesity. Pediatrics, 132(4), e1026-e1030. https://doi. org/10.1542/peds.2012-3940

Slane, J. D., Klump, K. L., McGue, M., \& lacono, W. G. (2014). Developmental trajectories of disordered eating from early adolescence to young adulthood: A longitudinal study. International Journal of Eating Disorders, 47(7), 793-801. https://doi.org/10.1002/eat.22329

Solmi, F., Hatch, S., Hotopf, M., Treasure, J., \& Micali, N. (2014). Prevalence and correlates of disordered eating in a general population sample: The South East London community health (SELCoH) study. Social Psychiatry and Psychiatric Epidemiology, 49(8), 1335-1346. https://doi. org/10.1007/s00127-014-0822-3

Sonneville, K., \& Lipson, S. (2018). Disparities in eating disorder diagnosis and treatment according to weight status, race/ethnicity, socioeconomic background, and sex among college students. International Journal of Eating Disorders, 51(6), 518-526. https://doi.org/10. 1002/eat.22846

Substance Abuse and Mental Health Services Administration. (2015). screening and assessment of co-occurring disorders in the justice system. HHS publication, (SMA)-15-4930.

Tomori, M., \& Rus-Makovec, M. (2000). Eating behavior, depression, and self-esteem in high school students. Journal of Adolescent Health, 26(5), 361-367. https://doi.org/10.1016/S1054-139X(98)00042-1

Truman, S. D., Sharar, D. A., \& Pompe, J. C. (2011). The mental health status of expatriate versus U.S. domestic workers: A comparative study. International Journal of Mental Health, 40(4), 3-18. https://doi.org/10. 2753/IMH0020-7411400401

UNESCO Institute of statistics (2015). Total enrollment in tertiary education (ISCED 5 to 8), regardless of age, expressed as a percentage of the total population of the five-year age group following on from secondary school leaving. World Bank EdStats. Retrived from https://data. worldbank.org/data-catalog/ed-stats

van Buuren, S. (2007). Multiple imputation of discrete and continuous data by fully conditional specification. Statistical Methods in Medical Research, 16(3), 219-242. https://doi.org/10.1177/0962280206074463

Wade, T. D., Wilksch, S. M., \& Lee, C. (2012). A longitudinal investigation of the impact of disordered eating on young Women's quality of life. Health Psychology, 31(3), 352-359. https://doi.org/10.1037/ a0025956

Wilsnack, R., Wilsnack, S., Gmel, G., \& Kantor, L. (2017). Gender differences in binge drinking: Prevalence, predictors, and consequences. Alcohol Research, 39(1), E1-E20.

Woodside, D. B., Garfinkel, P. E., Lin, E., Goering, P., Kaplan, A. S., Goldbloom, D. S., \& Kennedy, S. H. (2001). Comparisons of men with full or partial eating disorders, men without eating disorders, and women with eating disorders in the community. American Journal of Psychiatry, 158(4), 570-574. https://doi.org/10.1176/appi.ajp.158.4.570

Yanover, T., \& Thompson, J. K. (2008). Self-reported interference with academic functioning and eating disordered symptoms: Associations with multiple dimensions of body image. Body Image, 5(3), 326-328. https://doi.org/10.1016/j.bodyim.2008.03.008

Yu, Z., Indelicato, N. A., Fuglestad, P., Tan, M., Bane, L., \& Stice, C. (2018). Sex differences in disordered eating and food addiction among college students. Appetite, 129, 12-18. https://doi.org/10.1016/j.appet.2018.06.028

\section{SUPPORTING INFORMATION}

Additional supporting information may be found online in the Supporting Information section at the end of this article.

How to cite this article: Serra R, Kiekens G, Vanderlinden J, et al. Binge eating and purging in first-year college students: Prevalence, psychiatric comorbidity, and academic performance. Int J Eat Disord. 2020;53:339-348. https://doi. org/10.1002/eat.23211 